\section{O NÚCLEO DE CULTURA CLÁSSICA E A SOCIEDADE BRASILEIRA DE ESTUDOS CLÁSSICOS}

\author{
* Professora \\ Associada, \\ Programas de \\ Pós-Graduação em \\ Letras (PPGLetras) \\ e em Estudos da \\ Tradução (POET), \\ Universidade Federal \\ do Ceará.
}

amcpompeu@hotmail.com

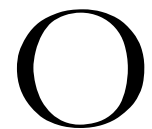
Núcleo de Cultura Clássica vinculado ao Departamento de Letras Estrangeiras do Centro de Humanidades da Universidade Federal do Ceará foi instituído por meio da RESOLUÇÃO no 2/CONSUNI de 28 de fevereiro de 1992 pelo então Magnífico Reitor Professor Antônio de Albuquerque Sousa Filho; é também um grupo do diretório do $\mathrm{CNPq}$, um grupo de pesquisa da Sociedade Brasileira de Estudos Clássicos - SBEC e um Programa de Extensão da Universidade Federal do Ceará.

Os fundadores do Núcleo de Cultura Clássica foram os Professores Eleazar Magalhães Teixeira e José Alves Fernandes (in memoriam), membros fundadores da SBEC. Eles são os responsáveis por difundir os Estudos Clássicos em Fortaleza e em todo o estado do Ceará. Através da SBEC, tivemos conhecimento dos demais pesquisadores de Estudos Clássicos no Brasil e de muitos pesquisadores estrangeiros, dos quais só conhecíamos as obras. A Classica - Revista Brasileira de Estudos Clássicos acompanha o histórico da SBEC e a formação do Núcleo de Cultura Clássica, bem como dos demais núcleos e grupos de Estudos Clássicos do Brasil.

Ao longo de seus vinte e sete anos de história, o NUCLAS desenvolveu e continua a promover uma série de atividades que visam à disseminação dos Estudos Clássicos no Ceará e no Brasil, como cursos de extensão, semanas temáticas, palestras, publicações e grupos de estudo.

Os cursos de extensão em grego são ofertados aos sábados, das $8 \mathrm{~h}$ às $12 \mathrm{~h}$, em três níveis: Introdução ao Grego Clássico e Koiné; Grego Clássico e Koiné Intermediário e Grego Clássico e Koiné Avançado. Cada nível com 128 horas/aula ofertado em dois semestres. 
Os cursos de extensão em grego e em latim são responsáveis pela formação em língua clássica de parte dos atuais professores do Núcleo. Após as aulas dos sábados, temos o encontro dos grupos de estudo: Grupo de Estudos da Comédia Aristofânica - GECA e Grupo de Estudos da Septuaginta - GES, coordenados pela Professora Ana Maria César Pompeu; Grupo - Estudos de Narrativa e Teatro - G-ente, coordenado pelo Professor Orlando Luiz de Araújo. Há o Grupo PAIDEIA, de Teatro de bonecos, que estuda mitologia e promove cursos de extensão em mitologia grega e romana, e o Grupo GENEA, que estuda a comédia nova e reúne os demais grupos que estudam o teatro antigo.

\section{Semana de Estudos Clássicos}

Um dos eventos mais importantes do calendário de atividades anuais do NUCLAS, bem como da própria Universidade Federal do Ceará, é a Semana de Estudos Clássicos, que, a cada ano, propõe um tema para discussão e debates, tanto de professores, quanto de alunos e, dessa forma, mobiliza a comunidade universitária e fortalezense em torno de um eixo comum de discussões voltadas para a reflexão sobre os Estudos Clássicos. As Semanas de Estudos Clássicos da UFC começaram em 1985. A partir de 2012, a Semana passou a acontecer a cada dois anos, para que houvesse tempo de publicar os trabalhos apresentados no evento. Os livros organizados a partir das Semanas de Estudos Clássicos foram os seguintes: Anais XXIX Semana de Estudos Clássicos Mundos Antigos, Perspectivas Modernas: Recepção e Autoria. Fortaleza: Substânsia, 2020; Anais XXVIII Semana de Estudos Clássicos: O feio e o torpe na Antiguidade e sua recepção. Fortaleza: Substânsia, 2017; Grécia e Roma no universo de Augusto. Coimbra: Imprensa da Universidade de Coimbra, 2015; Identidade e Alteridade no mundo antigo. Fortaleza: Expressão Gráfica e Editora; Oralidade, Escrita e Performance na Antiguidade. Fortaleza: Expressão Gráfica e Editora, 2013; O riso no mundo antigo. Fortaleza: Expressão Gráfica e Editora, 2012.

A Semana de Estudos Clássicos é uma via de ingresso nas práticas da vida acadêmica e nos processos, metodologia e divulgação da pesquisa científica. Durante sua realização os alunos podem não somente assistir às palestras de pesquisadores experientes, mas também participar de comunicações, minicursos e mesas redondas, apresentando seus próprios trabalhos com o resultado de suas pesquisas. Fica evidente, desse modo, que a Semana de Estudos Clássicos tem uma relevância inestimável na vida cultural e acadêmica da cidade de Fortaleza, com lugar de destaque no Nordeste, do ponto de vista regional e também do país, na medida em que congrega pesquisadores de vários estados e instituições de ensino nacionais, promovendo o intercâmbio e a mobilidade de pesquisadores a alunos, a transferência e o compartilhamento do conhecimento produzido em outras IES.

\section{Pesquisas do Núcleo de Cultura Clássica}

Atualmente, o NUCLAS é parte do Departamento de Letras Estrangeiras, lotado no Centro de Humanidades da UFC, no campus do Benfica, em Fortaleza, capital do estado 
do Ceará. Todos os seus membros são professores do curso de Licenciatura em Português e Letras Clássicas e participam de atividades em outros cursos da UFC (Instituto de Cultura e Arte, Departamento de Letras Vernáculas e Literatura, entre outros), sendo que alguns professores fazem parte do Programa de Pós-graduação em Letras (Literatura Comparada) - PPGLetras e da Pós-graduação em Estudos de Tradução - POET, ambos vinculados ao Centro de Humanidades da UFC.

Somos atualmente sete professores no Núcleo de Cultura Clássica, seis efetivos e uma visitante. Apresentaremos, a seguir, os professores, suas pesquisas e as pesquisas relacionadas dos seus orientandos de mestrado, doutorado e pós-doutorado.

Ana Maria César Pompeu é doutora e mestre em Letras Clássicas pela Universidade de São Paulo (1997/2004). Fez um estágio pós-doutoral na Universidade de Coimbra, em Portugal (2010). Atualmente, é Professora Associada da Universidade Federal do Ceará. Atua nos Programas de Pós-graduação em Letras (PPGLetras) e em Estudos da Tradução (POET). ${ }^{1}$ Sua pesquisa atual é "As Mulheres de Aristófanes: Lisistrata, Tesmoforiantes e Assembleia de Mulheres". A pesquisa tem como objetivo principal reconhecer a mulher como protagonista nas três comédias de Aristófanes, identificando a voz feminina do poeta cômico e analisando sua evolução, especialmente pela tradução de Assembleia de Mulheres como conclusão tradutória da trilogia feminina de Aristófanes (já foram traduzidas: Lisístrata - publicada em 1998 e em 2010, e Tesmoforiantes, publicada em 2015). A pesquisa tem como objetivos específicos: reconhecer o ambiente da Guerra do Peloponeso com suas consequências nas duas primeiras peças e a ausência da guerra na terceira peça, e descrever a composição e participação coral, observando a sua evolução nas três peças estudadas. Os projetos de pesquisa relacionados a sua pesquisa e que estão em andamento são os seguintes: "Imagens do feminino no Banquete de Platão: Sócrates e a flautista", do pós-doutorando Vicente Thiago Freire Brazil; "Drama gynaikos: a voz feminina nos lamentos fúnebres em As Troianas e Hécuba de Eurípides", da pós-doutoranda Joseane Mara Prezotto; "Aspecto verbal em Aristófanes: uma proposta cognitivo-funcional", do doutorando Fernando Henrique Pereira da Silva; "O iratus senex de Menandro a Terêncio", da doutoranda Stefanie Cavalcanti de Lima Silva; "A representação da Ave no Livro das Aves do Lorvão: tradução e análise", da mestranda Rosângela Nobre da Silva e "Intertextualidade e reescritura na tradução do livro de Esdras deuterocanônico", do mestrando Gilbson Gomes Bento. Os projetos de pesquisa relacionados a sua pesquisa e já

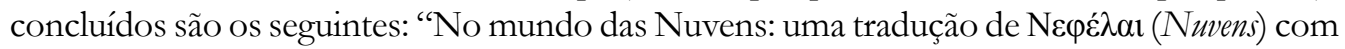
referência a acionalidade, referência temporal e aspecto verbal grego", do pós-doutorando Roque Nascimento Albuquerque (coorientação); "O riso da Musa no campo de batalha: as marcas da poética de Arquíloco na formação da persona poética na Comédia Ática”, do

\footnotetext{
${ }^{1}$ Publicou Aristófanes e Platão: a justiça na pólis (2011), Dioniso matuto: uma abordagem antropológica do riso na tradução de Acarnenses de Aristófanes para o cearensês (2014) e Acrópole, agora! Mulher, dentro! Homem, fora! Introducão à Lisístrata de Aristófanes (2018) e traduziu, de Aristófanes, Lisístrata (1998; 2010), Tesmoforiantes (2015), Cavaleiros (2017), e, de Plutarco, em colaboração, Epitome da comparação de Aristófanes e Menandro (2017). Organizou em colaboração os livros: O riso no mundo antigo (2012), Oralidade, escrita e performance na Antiguidade e Identidade e alteridade no mundo antigo (2013) e Grécia e Roma no universo de Augusto (2015).
} 
doutorando Márcio Henrique Vieira Amaro; "Aristófanes e Tucídides: a composição da Guerra do Peloponeso e seus protagonistas", do doutorando Rafael Ferreira Monteiro; "A(u) tos matutos de Ariano Suassuna e Aristófanes - É possível? Não sei só, sei que foi assim?”, do doutorando Francisco Jacson Martins Vieira; "Fiar, tramar, tecer: considerações sobre o silêncio e a voz das mulheres no mythos e em Aristófanes", da doutoranda Solange Maria Soares de Almeida; "A importância e a confiabilidade dos escólios de Acarnenses", do doutorando Lauro Inácio de Moura Filho; "O farsesco em Aristófanes", do doutorando Francisco Alison Ramos da Silva; "O Pluto de Aristófanes: estudo e tradução", do mestrando Kleber Bezerra Rocha.; "Tradução comentada e anotada dos escólios da parábase de Cavaleiros", do mestrando Fernando Henrique Pereira da Silva; "Lisistrata: estudo e adaptatradução para o teatro de bonecos", da mestranda Danielle Motta Araújo; "Um gole para Dioniso: sexo e subversão em Tesmoforiantes de Aristófanes", do mestrando Elvis Freire da Silva; "Hareios Poter: um estudo descritivo sobre a tradução dos nomes próprios de Harry Potter and the philosopher's stone para o grego antigo", do mestrando João Alfredo Ramos Bezerra; "O amor e a guerra em Aristófanes, a partir de uma leitura de Rãs", do mestrando Márcio Henrique Vieira Amaro; "Tecendo o universo feminino em Lisistrata: entre guerreiras divinas e mortais", da mestranda Milena Nobre; "O retrato das instituições judiciárias atenienses na comédia As Vespas, de Aristófanes", do mestrando Valdísio Vieira da Silva;. "Nuvens carregadas de ideias: o engraçado e o sério entre Estrepsíades e Sócrates na comédia de Aristófanes", da mestranda Solange Maria Soares de Almeida e "Transtextualidade e hermenêutica na comédia de Aristófanes: o poeta como mestre da cidade", do mestrando Lauro Inácio de Moura Filho.

Francisco Edi de Oliveira Souza, possui graduação (1997) e mestrado (2001) em Letras pela Universidade Federal do Ceará, doutorado (2008) em regime de co-tutela pela Universidade de São Paulo e pela Sorbonne (Paris IV), pós-doutorado (2013) pela Sorbonne (Paris IV). Atualmente é professor efetivo da Universidade Federal do Ceará. É doutorando em Filosofia pela UFC. ${ }^{2}$ Sua pesquisa atual é "Poesia latina, Retórica e Filosofia". Este projeto de pesquisa, de acordo com o professor, propõe em particular um exame da relação da obra elegíaca do poeta latino Sexto Propércio (c. 50-15 a.C.) com a filosofia. O estudo de um diálogo da elegia latina com a filosofia é pouco explorado, pois tal gênero é em geral considerado pouco profundo, pouco afeito à filosofia. A elegia amorosa latina revela-se contrária aos ditames sociais, à religião, à política e elege o Amor como tema de predileção;

\footnotetext{
${ }^{2}$ Tem experiência na área de Letras, com ênfase em língua e literatura latina, atuando principalmente nos seguintes temas: épica greco-latina e suas relações com outros gêneros poéticos; poesia de Virgílio e Propércio; poesia e retórica; poesia e filosofia. Publicações recentes: "Metamorfose da língua: um

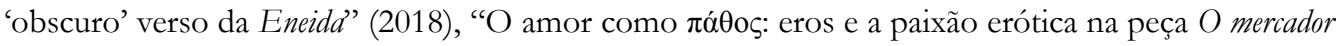
de Plauto" (2017), "O amor insano de Propércio em diálogo com a filosofia moral” (2014), "A Vênus insana de Propércio" (2011), "Grécia e Roma no universo de Augusto" (2015), "Tite-Live, Virgile et Bacchus: la figure du dieu entre historiographie et poésie” (2018), “Crudeli funere' e Baco na obra de Virgílio: elos de Júlio César, M. Antônio, Cleópatra e Otaviano” (2015), "Concepções da morte na obra de Propércio: tradição mítico-religiosa e filosofia" (2014), "Identidade e alteridade de gênero na obra de Propércio: 'elegia ou épica”' (2013).
} 
com esse modo de vida improbus e doentio, a elegia amorosa se reconhece como moralmente avessa às expectativas sociais e fora da reta razão; e essa condição apresenta-se como um malum que vai além da vontade racional. Esse conspecto sugere um distanciamento da filosofia; todavia, é justamente esse modo de vida o que instiga Propércio para a filosofia: sua persona elegíaca procura libertar-se desse malum e para tanto recorre à filosofia, em especial à feição terapêutica da filosofia helenística. Como esta pesquisa examina textos literários por um prisma mais abrangente, abre-se para projetos de mestrado e doutorado que discutam filosofia, retórica e questões de gênero poético na literatura latina. Os projetos de pesquisa de orientandos relacionados a sua pesquisa e já concluídos são os seguintes: "Interior Societas? A Amizade e a dialética entre interioridade e alteridade nas Cartas a Lucílio de Sêneca", da doutoranda Natália Vasconcelos Rodrigues Tatarek (coorientação); "A ira na Hecyra de Terêncio", da mestranda Stefanie Cavalcanti de Lima Silva; "A adivinhação na Pharsalia de Lucano", da doutoranda Pauliane Targino da Silva Bruno; "A linguagem poética na tradução da Eneida de Carlos Alberto Nunes: um estudo na perspectiva da teoria tradutória de Haroldo de Campos", da mestranda Francisca Tânia Almeida Colares (coorientação); "A elocução do amor em Tibulo", da mestranda Maria Helena Aguiar Martins; "Entre a épica e a elegia: a representação de Dido na poesia latina", da mestranda Natália Vasconcelos Rodrigues; "A narrativa de Euríbates na tragédia Agamêmnon de Sêneca: um diálogo entre gêneros", da mestranda Letícia Freitas Alves; "Estudo de gênero em As Geórgicas, de Virgílio", do mestrando Liebert de Abreu Muniz.

Joseane Mara Prezotto é doutora e professora colaboradora no Programa de PósGraduação em Letras - PPGLetras da Universidade Federal do Ceará. É doutora em Letras (2015) pela Universidade Federal do Paraná, onde atuou como professora substituta de Língua e Literatura Grega de 2014 a 2016. ${ }^{3}$ Sua pesquisa atual, de pós-doutorado, é “Drama gynaikos: a voz feminina nos lamentos fúnebres em As Troianas e Hécuba de Eurípides". O projeto propõe uma pesquisa transdisciplinar sobre a voz feminina no período grego clássico através do estudo de cantos de lamento fúnebre em dramas trágicos supérstites, com foco nas peças As Troianas e Hécuba de Eurípides. O percurso ao encontro dessa voz prevê a comparação diacrônica desses cantos a tradições reminiscentes em comunidades dos Balcãs, principalmente regiões da Grécia Antiga e Moderna. Pretende-se discutir, por meio da revisão, contextualização e comparação, características estruturais e performativas (genre

\footnotetext{
${ }^{3}$ Tem experiência no ensino de Línguas Clássicas (grego e latim), nas áreas de Língua e Literatura Grega Antiga e de História e Filosofia da Linguística, bem como Linguística e Língua Portuguesa. Em seus estudos formativos, interessou-se pela História da Gramática, Gramática Antiga, Retórica, Sofística, Ceticismo, Epicurismo, Estoicismo e Filologia Helenística. Traduziu o tratado anônimo sofístico Dissoi Logoi (Trans/for/ma/ção, 2017) e o Contra os Gramáticos, do filósofo cético Sexto Empírico (PhaoS, 2017; Hypnos, 2018; Archai, 2018; Anais de Filosofia Clássica, 2018; Nuntius Antiquus, 2019). Participou dos livros A comédia e seus duplos: o Anfitrião de Plauto (Kötter, 2017) e Retórica: Perspectiva Histórica e Atualidade (Mercado de Letras, 2018). Participou das traduções de Oikeios Logos: linguagem, dialética e lógica em Antístenes, de Aldo Brancacci (Ed. PUC-Rio e Ed. Loyola, 2019) e de Aristóteles: on o Vampiro do Teatro Ocidental, de Florence Dupont (Editora Cultura e Barbárie, 2018).
} 
issues) de lamentos femininos na tragédia em sua relação com a configuração da sociedade grega clássica, priorizando questões culturais de gênero (gender issues), como um fator de tensão produtiva permanente naquele universo. Propõe-se deslocar apropriações teóricas tradicionais dos cantos trágicos, aproximando seus aspectos de oralidade e sua estrutura performativa e ritualística à estrutura de realização de lamentos femininos tradicionais, antigos e modernos. Assim, uma ponte de ligação emocional e estética com aqueles cantos poderá ser construída. Os objetivos desse empreendimento dizem respeito, portanto, à investigação de um gênero de poesia popular oral incorporado no que será um dos gêneros literários mais importantes da história cultural do ocidente. Os projetos de pesquisa de orientandos relacionados ao seu projeto e que estão em andamento são: "Parmênides, Da natureza e o problema da tradução de obras poético-filosóficas", do mestrando Ítalo Vieira Lima e "Édipo Rei e o Rei dos Judeus: um estudo comparativo do sacrifício na literatura”, do mestrando Carlos Luiz de S. Oliveira.

Josenir Alcântara de Oliveira é Professor Associado IV de Língua Latina e Filologia Românica na Universidade Federal do Ceará. Tem graduação em Letras (Português/Inglês) e especialização em Literatura Brasileira, pela Universidade Estadual do Ceará; mestrado em Filologia Românica e doutorado em Filologia e Língua Portuguesa pela Universidade de São Paulo. ${ }^{4}$ Seu projeto de pesquisa atual é "A etimologia em Etymologiae de Santo Isidoro". Um dos maiores expoentes da Idade Média, Santo Isidoro faz das Etymologiae uma enciclopédia do mundo romano. Nesta pesquisa, de acordo com o professor, objetiva-se não só apresentar o perfil técnico da etimologização isidoriana, mas também colher as etimologias plausíveis perante a ciência etimológica moderna.

Orlando Luiz de Araújo é Professor Associado da Universidade Federal do Ceará onde atua na graduação em Letras, Filosofia e Teatro, e no Programa de Pós-Graduação em Letras, Literatura Comparada. Possui Doutorado e Mestrado em Letras Clássicas pela Universidade de São Paulo, Especialização em Filosofia Política e Licenciatura em PortuguêsLiteratura pela Universidade Federal do Ceará. ${ }^{5}$ Sua pesquisa atual é "Narração e drama:

\footnotetext{
${ }^{4}$ Publicou "A homonímia e a polissemia" no Dicionário Etimológico da Lingua Portuguesa de J. P. Machado. (2005), "Os grandes temas do vocabulário gírio da cachaça" (1995), "O homem e a mulher à luz da etimologia" (1994), "Uma leitura onomasiológica do ler" (2013), “A onomástica em Plauto” (2012), "Agostinho e a etimologia" (2012), "Homonímia e polissemia em Pokorny" (2006), "O trabalho no universo indo-europeu: uma interpretação etimológico-onomástica” (2013).

5 Tem experiência na área de Letras, com ênfase em Língua e Literatura e em Tradução, atuando principalmente nos seguintes temas: língua e literatura grega e tradução de textos clássicos, mitologia grega e gêneros literários na Antiguidade Greco-Romana. Traduziu Electra de Sófocles e organizou em coautoria Identidade e Alteridade no Mundo Antigo, Performance e Oralidade no Mundo Antigo, O Riso no Mundo Antigo e Ensaios em Estudos Clássicos. É membro do Grupo de Pesquisa Estudos sobre o Teatro Antigo (USP/CNPQ). Traduziu Calígula, de Albert Camus, para encenação pela companhia teatral Comedores de Abacaxi S/A. Desenvolve o projeto Gêneros em diálogos na Literatura Grega Antiga, especificamente, a tradução de Dos amores apaixonados, de Partênio de Niceia, e o estudo da relação literatura, teatro, história e mitologia nas narrativas de amor. Realizou um Pós-Doutorado com bolsa CAPES (Processo No 99999.000773/2015-08) no Centro de Estudos Clássicos da Faculdade de Letras da Universidade de Lisboa, com o projeto intitulado "Dos Amores Apaixonados, de Partênio de Niceia: tradução, alusão e diálogos de gêneros".
} 
gêneros em diálogos na literatura grega antiga". A pesquisa, de acordo com o professor, tem como objetivo investigar a relação dialógica entre narrar e representar, a partir das teorias modernas sobre a narrativa e o drama aplicadas à literatura grega antiga, especialmente, à poesia épica e ao drama trágico. A aplicação da teoria da narrativa ao drama ajudará a melhor compreender questões relevantes para a tragédia grega, como, por exemplo, o papel da narração de sonhos, das revelações oraculares e dos relatos de mensageiros, propriedades da narrativa, que estão presentes no drama; assim como ajudará a desmontar as armadilhas planejadas pelos narradores/intérpretes no texto teatral antigo. Os projetos de pesquisa de orientandos que são relacionados ao seu projeto e estão em andamento são: "A metáfora em Platão: entre o discurso retórico e filosófico", da pós-doutoranda Jovelina Maria Ramos de Souza; "Recepção de Antígona na Literatura Brasileira", do doutorando Renato Cândido da Silva; "Espaço ficcional na comédia de Aristófanes", do doutorando Paulo César de Brito Telles Junior; "Das faces de thánatos: escatologia e política nas Histórias de Heródoto", da doutoranda Edilane Vitório Cardoso; "Dos muros de Troia aos sertões gerais: de Ilíada a Grande Sertão: Veredas", da mestranda Edinaura Linhares Ferreira Lima; "O Frankenstein existencialista: uma perspectiva sartriana da criatura como metáfora para existência humana (e o mito de Prometeu)", da mestranda Mellyssa Coêlho de Moura e "Hesíodo e a Narrativa Bíblica", da mestranda Jacqueline Silva Bastos. Os projetos de pesquisa de orientandos relacionados a sua pesquisa e já concluídos são os seguintes: "O feminino em Electra de Sófocles e de Eurípides", da mestranda Marcelle Pereira Santos; "Pedreira das Almas e Antígona: o rastro do trágico", do mestrando Renato Cândido da Silva; "Suplicantes, de Eurípides: estudos e tradução", da mestranda Vanessa Silva Almeida; "Um vislumbre do divino: a narrativa que acompanha a possessão de personagens no drama trágico grego", do mestrando Pedro Leno de Jesus da Silva; "Diálogos da mitologia grega com os contos Petúnia, O Convidado e O Lodo, de Murilo Rubião", da mestranda Camila Sâmia da Silva Souza; "Trenos kai goos: lágrimas e murmúrios de Andrômaca", do mestrando Luciano Heidrich Bisol; "Drama tecido em palavras: multiplicidades de Helena no teatro de Eurípides", da mestranda Cíntia Araújo Oliveira; "Platão: crítico e herdeiro da Tradição", do mestrando Rummenigge Santos da Silva (Coorientação); "De exílio em exílio - um diálogo entre Eurípides e Clara de Góes na peça Medea en Promenade", da mestranda Francisca Luciana Sousa da Silva; "Narrativa Histórica de Tucídides e a Guerra do Peloponeso: verdade e ficção", do mestrando Rafael Ferreira Monteiro; "Do mito à cena: Agamêmnon entre Grécia e Roma", da mestranda Pauliane Targino da Silva Bruno e "Destino e devir nos fragmentos de Heráclito e n'As Traquínias, de Sófocles", do mestrando Francisco Alison Ramos da Silva.

Robert de Brose ${ }^{6}$ é professor adjunto de Letras Clássicas e Tradução da Universidade Federal do Ceará (Campus de Fortaleza). Bacharel em Língua e Literatura Grega, mestre

\footnotetext{
${ }^{6}$ Foi coordenador do Programa de Pós-graduação em Estudos da Tradução (POET) da Universidade Federal do Ceará entre julho de 2016 e agosto de 2018 (vice-coordenador entre outubro de 2015 a junho de 2016). Foi vice-presidente do GT/ANPOLL Estudos da Tradução (biênio 2016-2018) e coordenou o encontro do GT no XXXIII Encontro Nacional da ANPOLL (Cuiabá/ 2018). É líder do Grupo de Pesquisa no CNPq “Tradução e Recepção dos Clássicos” e "Translational Hermeneutics,
} 
e doutor com distinção e louvor em Letras Clássicas pela Universidade de São Paulo. Seu projeto de pesquisa atual é "Tradução, recepção e filologia clássica". Esse projeto de pesquisa, de acordo com o professor, busca investigar de que maneira o método filológico tradicional, baseado na fidelidade da transmissão textual, pode contribuir na tradução, a partir de várias vertentes teóricas, e na disseminação das obras da Antiguidade Clássica no mundo moderno. Incluída aí está a investigação da recepção dessas obras na modernidade em diversas línguas e culturas. Na outra direção, de que forma diferentes teorias da tradução podem ajudar na translação de textos pertencentes a culturas e línguas que já não existem mais. Os projetos de pesquisa de orientandos relacionados a sua pesquisa e que estão em andamento são:" "Estudo e tradução de Batracomiomaquia de Pseudo-Homero", do mestrando Antônio Ricardo Paixão dos Santos; "De cócoras com ele: estudo, tradução e notas da peça $A s$ Rãs de Aristófanes", da mestranda Manuela Maria Campos Sales e "Estudo e tradução de Zózimo, alquimista grego da época helenística", da mestranda Rubia Santiago Menezes Bento Gonzaga.

Roberto Arruda de Oliveira é professor associado III da Universidade Federal do Ceará, onde leciona Língua Latina, Filologia Românica, Cultura Clássica e Literatura Latina no Ensino Presencial (Graduação), Língua Latina e Filologia Românica no Semi-presencial (Graduação). Defendeu dissertação de Mestrado sobre a Bucólica IV de Virgílio (UFRJ) e tese de Doutorado sobre as Elegias de Propércio (UFRJ). Desenvolveu também pesquisa na área de Filologia Portuguesa. ${ }^{8}$ Seu projeto de pesquisa atual é "Do latim às línguas românicas (séc. XX)". De acordo com o professor, os estudos básicos de língua latina do curso de Letras permitem vislumbrar novas perspectivas que se apresentam a partir dos estudos históricos de nosso idioma. O conhecimento da língua portuguesa não pode se limitar a seu momento atual. Precisa-se vislumbrar seu processo de formação, suas origens, os aspectos que determinaram seu sistema escrito e o fonológico. Para isso vale-se neste trabalho da base

Cognition and Creativity". Organizador do selo Ecos de tradução para a Editora Substânsia, membro do comitê editorial da Revista Translatio, da Revista Cadernos de Tradução (UFSC) e da Coleção Palavra de Tradutor (UFSC). Sua tese de doutorado foi escolhida como melhor Tese do ano de 2014 na Área de Estudos Clássicos e publicada com o título Epikomios Hymnos: investigações sobre a performance nos epinícios pindáricos pela Série Produção Acadêmica Premiada da Editora Humanitas. Atualmente, dedica-se à tradução da obra completa de Píndaro, cujo projeto foi contemplado com o Edital Universal MCTI/ CNPQ 2014, de uma antologia de lírica grega arcaica e da composição de um manual de metro e ritmo da poesia grega antiga (Edital Universal MCTI/CNPq 2019). É visiting scholar na Faculty of Classics, Universidade de Oxford desde junho de 2019. Possui também um blog de tradução de poesia, Versos(re)Versos, http://versosemreverso.blogspot.com.

${ }^{7}$ Projeto de pesquisa já concluído: "Estudo crítico do processo de compilação, seleção de textos e tradução (grego-francês) da Coleção Hipocrática por Émile Littré”, do mestrando Henrique Antônio Fonseca da Mota Filho.

8 Artigos publicados recentemente: "Virgílio e a 'aetas aurea' augustana", 2015; "Vocalismos e consonantismos na România”, 2015; "Imaginário da morte nas elegias de Propércio”, 2016; "Legado das categorias nominais latinas", 2016; "Roma Antiga: becos e ruelas fétidos", 2017; "Século XVIII: o iluminismo lexicográfico", 2017; "Propércio: inspiração e linguagem”, 2018; "Percepções da Idade de Ouro nos poetas augustanos”, 2019. 
gramatical latina, elemento sem o qual não seria viável demonstrar a formação do idioma nacional a partir de sua língua-mãe. Neste projeto são contemplados não só o vernáculo como também as outras línguas românicas que se inserem igualmente neste contexto linguístico. O legado cultural e linguístico do povo romano permanece indelével em todos os territórios por eles colonizados. Sem dúvida alguma, levavam as legiões em suas armas o denominado latim vulgar, o qual, por ser mais popular, imprimiu sua marca nas línguas que são motivo de análise nesse projeto.

\section{Missão do Núcleo de Cultura Clássica}

Nossa missão é oferecer cursos em grego, latim e sânscrito, tanto para alunos da UFC quanto para membros da comunidade, bem como promover diferentes atividades culturais que tenham por objetivo difundir o conhecimento da Antiguidade entre um público mais amplo, a fim de chamar a atenção para a importância dos clássicos em nossa sociedade moderna. No nível acadêmico, um dos nossos objetivos mais importantes é produzir e fomentar a pesquisa em Estudos Clássicos, conectando professores e pesquisadores nacionais e internacionais com o intuito de promover, compartilhar e difundir o conhecimento através de uma rede colaborativa de profissionais e estudantes que tenham interesses similares. Nossa ambição é nos tornarmos um centro de referência na pesquisa em Estudos Clássicos tanto no Brasil quanto no exterior, especializando-nos em educar jovens pesquisadores para que eles possam se tornar tradutores, editores e pesquisadores competentes em grego, latim e sânscrito, bem como acadêmicos capazes de perseguir uma carreira tanto em universidades brasileiras quanto internacionais. Nossos valores são: a) compromisso com um alto padrão em procedimentos de pesquisa e ensino; b) interesse no desenvolvimento científico e cultural da comunidade a que a UFC e o NUCLAS se ligam; c) compromisso com a promoção dos Estudos Clássicos no Brasil e d) transparência no acesso à informação e às atividades do NUCLAS. Nosso mote é pulchra colamus ("cultivemos as coisas belas") e o nosso logo é o gorgoneion como pintado por Ergotimos (figura negra, ca. 570 a.C.) na tampa de uma ânfora em terracota. O gorgoneion não é apenas a efígie de um monstro terrível, mas sobretudo um poderoso apotropaico contra as forças do mal e do caos, tanto que foi dado por Perseu a Atena, deusa do conhecimento e da sabedoria, para que essa o colocasse no meio de seu escudo. Em alguns relatos e representações, ele também aparece como o botão da fivela que prendia as duas pontas da aegis da deusa (ou de Zeus). O gorgoneion, portanto, representa os perigos e as dificuldades que se deve enfrentar para se obter o conhecimento. Como guardião da sabedoria, ele se mantém entre nós e a deusa e, se quisermos chegar até ela, será preciso, primeiro, olhar em seus olhos e enfrentá-lo.

\footnotetext{
${ }^{9}$ Cf. http://www.nuclas.ufc.br
} 


\section{REFERÊNCIAS}

BROSE, R. de; ARAUjO, O. L.; POMPEU, A. M. C. Oralidade, Escrita e Performance na Antiguidade. Fortaleza: Expressão Gráfica Editora, 2013.

POMPEU, A. M. C.; ARAÚJO, O. L. Anais XXIX Semana de Estudos Clássicos Mundos Antigos, Perspectivas Modernas: Recepscão e Autoria. Fortaleza: Substânsia, 2020.

POMPEU, A. M. C.; ARAÚJO, O. L.; BROSE, R. de. O riso no mundo antigo. Fortaleza: Expressão Gráfica e Editora, 2012.

POMPEU, A. M. C.; BROSE, R.; ARAUJO, O. L.; OLIVEIRA, R. A. Identidade e Alteridade no mundo antigo. Fortaleza: Expressão Gráfica e Editora.

POMPEU, A. M. C.; SOUSA, F. E. O.; ARAUJO, O. L. Anais XXVIII Semana de Estudos Clássicos: O feio e o torpe na Antiguidade e sua recepscão. Fortaleza: Substânsia, 2017.

POMPEU, A. M. C.; SOUSA, Francisco Edi de Oliveira. Grécia e Roma no universo de Angusto. Coimbra: Imprensa da Universidade de Coimbra, 2015.

http://www.nuclas.ufc.br 